\title{
Healing with basic fibroblast growth factor is associated with reduced indomethacin induced relapse in a human model of gastric ulceration
}

\author{
M A Hull, A Knifton, B Filipowicz, J L Brough, G Vautier, C J Hawkey
}

\begin{abstract}
Background-Acid stable basic fibroblast growth factor (bFGF) promotes angiogenesis and healing of gastric ulcers in rats and reduces subsequent non-steroidal anti-inflammatory drug (NSAID) induced relapse.

Aims-To test in a double blind, placebo controlled, three way crossover study whether bFGF promotes healing and reduces subsequent relapse in a human model of gastric ulceration.

Subjects-Twelve healthy volunteers.

Methods-Subjects took aspirin $900 \mathrm{mg}$ twice daily (days 1-3) with bFGF 0.1 mg twice daily or cimetidine $400 \mathrm{mg}$ twice daily or placebo (days 1-14) and then indomethacin $50 \mathrm{mg}$ thrice daily (days 15-21). Endoscopy was performed on days $1,4,8,15$, and 22 during each treatment period. Eight antral biopsy specimens were taken on day 1 and the number of unhealed biopsy induced mini-ulcers and NSAID induced erosions counted during subsequent endoscopies.

Results-Basic FGF and cimetidine were protective against aspirin and indomethacin induced duodenal (but not gastric) injury compared with placebo. There was significant relapse of biopsy induced mini-ulcers after indomethacin only in the placebo group (0 (0-0) before $v 1(0-4 \cdot 5)$ after; $p>0.05)$. TGP-580 was detected in serum of one volunteer.

Conclusions-Healing with bFGF (and cimetidine) was associated with reduced NSAID induced ulcer replapse in this model of gastric ulceration.

(Gut 1997; 40: 204-210)
\end{abstract} gastric ulcer, non-steroidal anti-inflammatory drugs, prostaglandins.

Gastroenterology,

University Hospital, Queen's Medical Centre, Nottingham M A Hull

A Knifton

B Filipowicz

J L Brough

G Vautier

C J Hawkey

Correspondence to:

Dr M A Hull,

Division of Gastroenterology,

University Hospital,

Queen's Medical Centre,

Nottingham NG7 2UH.

Accepted for publication

6 September 1996

factory. ${ }^{2}$ If NSAID therapy is continued, gastric ulcer healing is often followed by recurrence $\left(>50 \%\right.$ at six months). ${ }^{3}$ Misoprostol (a prostaglandin $\mathrm{E}_{1}$ analogue) has been shown to reduce gastric ulcer recurrence ${ }^{4}$ but diarrhoea is common and often necessitates
Keywords: basic fibroblast growth factor, cimetidine,

cessation of treatment. ${ }^{5}$ Early studies demonstrated no benefit of $\mathrm{H}_{2}$ receptor antagonists for prevention of gastric ulceration. ${ }^{6}$ However maintenance high dose famotidine has recently been reported to lower gastric ulcer recurrence after healing. ${ }^{3}$

The mechanism by which NSAIDs impair ulcer healing and promote recurrence is not well understood although inhibitory actions on granulation tissue angiogenesis ${ }^{7}$ and ulcer rim epithelial cell proliferation ${ }^{8}$ have been reported in humans. There is evidence that mucosal abnormalities persist at the site of an ulcer for some time after ulcer healing ${ }^{9}$ and this may explain why gastric ulcers tend to recur at the same site. ${ }^{10}$ These findings have led to the idea of 'quality of healing' of ulcers - that is, the thickness of the mucosal scar, the depth of new epithelium, and continuity of muscularis mucosae. ${ }^{11}$ It has been proposed that impairment of ulcer healing mechanisms may reduce 'quality of healing' and predispose healed gastric mucosa to future ulceration.

Basic fibroblast growth factor (bFGF) is an $18 \mathrm{kDa}$ protein found in normal human gastric mucosa, ${ }^{12}$ which is upregulated in ulcer granulation tissue. ${ }^{13}$ Preliminary studies in humans have shown that gastric ulcers are associated with low bFGF levels in intact mucosa suggesting bFGF 'deficiency' may underlie a predisposition to ulceration. ${ }^{13}$ Basic FGF has potent angiogenic properties in vitro and in vivo. ${ }^{14} \mathrm{~A}$ more acid stable form of $\mathrm{bFGF}$ (bFGF CS-23 or TGP-580; Takeda Chemical Industries, Osaka, Japan) promotes angiogenesis and healing of acetic acid induced gastric ulcers ${ }^{15}$ and cysteamine induced duodenal ulcers ${ }^{16}$ in rats. We have shown, in an open, pilot study, that oral bFGF therapy in patients with NSAID associated gastric ulcers is associated with a healing rate of $44 \%$ at one month and a mean $90 \%$ reduction in area of unhealed ulcers. ${ }^{17}$ Recent evidence suggests that healing of acetic acid induced ulcers in rats with bFGF is associated with a reduction in indoNon-steroidal anti-inflammatory drugs methacin induced ulcer relapse after cessation of (NSAIDs) promote peptic ulceration ${ }^{1}$ and bFGF therapy (Satoh $\mathrm{H}$, personal communidelay ulcer healing. ${ }^{2}$ Currently available drug cation). A reduction in NSAID induced ulcer therapy for healing and secondary prevention relapse by 'angiogenic' therapy could be exof NSAID associated gastric ulcers is unsatis- plained by improved 'quality of healing'."

Acute aspirin induced mucosal injury in healthy volunteers is a well established model and has proved to be predictive of the effects of both prostaglandins and $\mathrm{H}_{2}$ receptor antagonists when given as prophylaxis against NSAID associated ulcers in patients. $^{18} 19$ 
Recently, we $\mathrm{e}^{20}$ and others ${ }^{21} 22$ have extended this model to permit investigation of healing mechanisms using biopsy induced mini-ulcers as a model of ulcer healing. In this paper we investigate the effects of indomethacin on relapse of mini-ulcers in healthy volunteers and compare the effects of bFGF and cimetidine on this as well as on prevention and healing of apsirin and indomethacin induced mucosal injury.

\section{Methods}

Ethical approval and volunteer recruitment

The study was approved by the University of Nottingham Medical School Ethics Committee. Volunteers of either sex were studied if they were aged between 18 and 45 years and were within $10 \%$ of desirable weight (according to Metropolitan Life tables). Volunteers were excluded if they were smokers, had a history of dyspepsia, peptic ulceration or malignancy or were women of child bearing potential not using medically acceptable means of contraception. Other exclusion criteria were presence of anaemia, a bleeding diathesis or use of concomitant medication except oral contraceptives. Written informed consent was obtained from all volunteers.

\section{Study design}

The study was a double blind, three way, placebo controlled crossover trial with randomised treatment order determined by Latin square design. A washout period of at least 14 days was included between treatment periods.

\section{Drug therapy}

Figure 1 outlines drug therapy administered during each treatment period. Volunteers took aspirin $900 \mathrm{mg}$ twice daily for the first three days, one hour after the first endoscopy and 30 minutes before meals to induce acute mucosal injury. Volunteers also started on day 1: TGP$580(0 \cdot 1 \mathrm{mg}$ twice daily) and sodium bicarbonate $\left(\mathrm{NaHCO}_{3} ; 1 \mathrm{~g}\right.$ twice daily); cimetidine (400 $\mathrm{g}$ twice daily) and $\mathrm{NaHCO}_{3}$ ( $1 \mathrm{~g}$ twice daily); placebo and $\mathrm{NaHCO}_{3}$ (1 g twice daily).

Placebo for both TGP-580 and cimetidine were given where appropriate. TGP-580 (acid stable bFGF) was given as $0 \cdot 1 \mathrm{mg}$ active drug

TGP-580 (bFGF)/cimetidine/placebo $+\mathrm{NaHCO}_{3}$

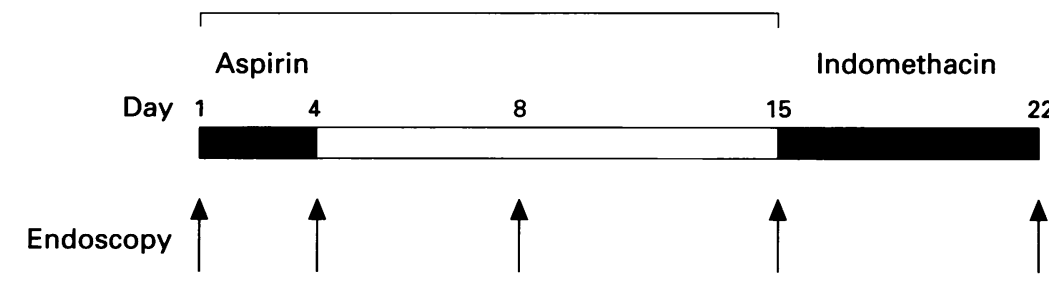

Figure 1: Outline of each of three treatment periods undertaken by volunteers. Aspirin 900 mg twice daily was administered for three days after initial endoscopy. TGP-580 (bFGF;

$0.1 \mathrm{mg}$ twice daily) or cimetidine ( $400 \mathrm{mg}$ twice daily) or placebo and sodium bicarbonate $\left(\mathrm{NaHCO}_{3} ; 1 \mathrm{~g}\right.$ twice daily) were started concurrently and stopped after 14 days.

Indomethacin 50 thrice daily was administered for the next seven days. Endoscopies were carried out on days $1,4,8,15$, and 22 . A washout period of at least 14 days was included between treatment periods. in $0.5 \mathrm{~g}$ dextran powder, which was dissolved in a glass cup of tap water along with $1 \mathrm{~g}$ $\mathrm{NaHCO}_{3}$ powder. TGF-580 placebo was given in a similar fashion. Cimetidine $400 \mathrm{mg}$ twice daily and placebo were given in capsule form and were taken at the same time as TGP580/placebo and $\mathrm{NaHCO}_{3}$. These drugs were taken immediately after meals (at least 30 minutes after aspirin ingestion). On day 15, all drugs were stopped and volunteers were given indomethacin capsules (50 mg thrice daily) for seven days (Fig 1). Volunteers were asked to abstain from alcohol during treatment periods.

\section{Endoscopy}

Unsedated upper gastrointestinal endoscopy was performed on days $1,4,8,15$, and 22 of each treatment period (Fig 1). To ensure consistency of evaluation, $89 \%$ of endoscopies were performed by one author (MH). Other endoscopies were carried out by two experienced endoscopists.

At each endoscopy, the number of erosions (haemorrhagic and non-haemorrhagic) was recorded separately for the oesophagus, stomach, and duodenum.

At endoscopy on day 1 (baseline), eight antral floor biopsy specimens $(\mathrm{A}-\mathrm{H})$ were taken in a straight line, $1 \mathrm{~cm}$ from the pylorus (measured using a custom made endoscopic measuring device). ${ }^{16}$ Each biopsy specimen was at least $1 \mathrm{~cm}$ away from neighbouring samples. All specimens were taken using the same forceps (FB-25K, Olympus, Tokyo, Japan). Two biopsy specimens were placed in $10 \%$ formalin for histological examination. Two biopsy specimens were used for measurement of ex vivo prostaglandin $\mathrm{E}_{2}$ synthesis. Breached mucosa at each biopsy site was designated a mini-ulcer and its position carefully noted for assessment of subsequent healing and future relapse. A biopsy induced miniulcer was recorded as healed if no defect in mucosa was visible endoscopically.

At endoscopy on day 4 (post-aspirin), the number of biopsy induced mini-ulcers $(\mathrm{A}-\mathrm{H})$ remaining unhealed was counted. Two pairs of biopsy specimens were taken for mesaurement of ex vivo prostaglandin $\mathrm{E}_{2}$ synthesis; one pair from the first two pre-existing biopsy induced mini-ulcers (A-B) and one pair from intact antral mucosa distant from existing mini-ulcers (L-M).

Endoscopy was repeated on day 8 (healing phase) and 15 (pre-indomethacin) and the number of unhealed biopsy induced miniulcers (A-H) was recorded. On day 15 two further antral biopsy specimens were taken from intact mucosa for measurement of ex vivo prostaglandin $\mathrm{E}_{2}$ synthesis (N-P).

After seven days of indomethacin treatment, volunteers underwent a final endoscopy (day 22). The number of biopsy induced miniulcers (A-H), which had recurred in prerecorded positions, was counted and fresh samples were taken from intact mucosa and unhealed biopsy induced mini-ulcers produced just before indomethacin therapy (N-P). 
Blood and urine sampling

Blood was obtained from each volunteer before the start of the study for routine haematological (full blood count, white cell count, and clotting screen) and biochemical (urea and electrolytes, plasma glucose, liver function tests, serum amylase) investigations. Urine was obtained for dipstick analysis of protein, blood, and glucose. A commercially available pregnancy test was also carried out on urine of female volunteers. At the end of the study the investigations carried out above were repeated.

At each endoscopy blood was taken and allowed to clot at $37^{\circ} \mathrm{C}$ for 60 minutes. Serum was then stored at $-30^{\circ} \mathrm{C}$ before assay of serum thromboxane $\mathrm{B}_{2}$ and serum TGP-580 concentrations.

Serum thromboxane $B_{2}$ measurement

Serum thromboxane $\mathrm{B}_{2}\left(\mathrm{TXB}_{2}\right)$ was measured by radioimmunoassay as previously described. ${ }^{23}$ Results are expressed as $\mathrm{ng} / \mathrm{ml}$ of serum.

\section{Serum TGP-580 measurement}

Serum TGP-580 was measured by sandwich ELISA. Briefly, serum and standards were added to phosphate buffered saline (PBS) containing $100 \mu \mathrm{g} / \mathrm{ml}$ heparin (Sigma, Poole, UK) and $1 \mathrm{mg} / \mathrm{ml}$ mouse IgG (Sigma) and were placed in 96 well plates coated with $(25 \mu \mathrm{g} / \mathrm{ml})$ murine monoclonal antibody against TGP-580 (ATI-3, Takeda). ATI-3 shows no cross reactivity with wild type bFGF up to $1000 \mathrm{pg} /$ $\mathrm{ml}$ (data not shown). After overnight incubation at $4^{\circ} \mathrm{C}$ and PBS washes, the Fab' fragment of a murine monoclonal anti-bFGF antibody ( $3 \mathrm{H} 3)$ conjugated with horseradish peroxidase (Takeda) was added to each well ( 3 $\mu \mathrm{g} / \mathrm{ml}$ ) and incubated for four hours at room temperature. After further PBS washes, OPD/ $\mathrm{H}_{2} \mathrm{O}_{2}$ was added and absorbance at $490 \mathrm{~nm}$ was measured at 60 minutes after stopping the reaction within $2 \mathrm{M} \mathrm{H}_{2} \mathrm{SO}_{4}$.

The intra-assay and inter-assay coefficients of variation for the TGP-580 ELISA were 8\% and $17 \%$ respectively. Limit of detection was $3 \mathrm{pg} / \mathrm{ml}$.

Ex vivo prostaglandin $E_{2}$ synthesis measurement Ex vivo prostaglandin $\mathrm{E}_{2}\left(\mathrm{PGE}_{2}\right)$ synthesis was measured as follows. Two antral biopsy specimens were washed in $1 \mathrm{ml} 10 \mathrm{mM}$ TRIS-

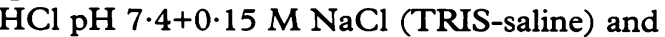
then vortexted for 60 seconds in $500 \mu$ l TRISsaline. The supernatant was collected and stored at $-70^{\circ} \mathrm{C}$ before assay of $\mathrm{PGE}_{2}$ using a radioimmunoassay as previously described. ${ }^{24}$ The net weight of the biopsy specimens was then measured. Results are expressed as $\mathrm{pg} / \mathrm{mg}$ wet weight of specimen.

\section{Histological assessment}

Formalin fixed biopsy specimens were embedded in paraffin wax. Sections were stained with haematoxylin and eosin and toluidine blue. The presence or absence of Helicobacter pylori was recorded by a histopathologist blinded to the origin of the sections.

Histological assessment was carried out on biopsy specimens taken on day 1 (baseline) for each of three treatment periods per volunteer.

\section{Adverse event reporting}

Volunteers were questioned about new or continuing symptoms, or both, at each endoscopy and were told to contact the endoscopist if new symptoms developed between visits.

\section{Statistical analysis}

The number of erosions and unhealed biopsy induced mini-ulcers present are expressed as the median value with interquartile range (IQR). Differences in erosion and unhealed biopsy induced mini-ulcer counts at different time points were compared within treatment groups by the Wilcoxon signed rank test for paired data. Differences between treatment groups were analysed by the Wilcoxon rank sum test adjusting for period effects by Koch's method for a two period cross over adapted for a three period cross over using SAS (version 6.08). ${ }^{25}$ Prostaglandin $\mathrm{E}_{2}$ and thromboxane $\mathrm{B}_{2}$ data were normally distributed and were analysed using Student's $t$ test.

A value of $p$ less than 0.05 was taken as significant and $p$ less than $0 \cdot 1$ as of borderline significance.

\section{Results}

Twelve volunteers underwent all three treatment periods. One volunteer declined to continue the study after completing one treatment period because of intolerance of endoscopic procedures. All data were included for statistical analysis. Mean (SEM) age of volunteers was 26 (1) years (eight male). All volunteers were Helicobacter pylori negative.

The mean (SEM) washout period between treatments was 37 (3) days (range 14-70 days).

\section{Healing of biopsy induced mini-ulcers}

Eight antral biopsy induced mini-ulcers were produced on day 1 in all cases. Biopsy site lesions were easily distinguishable from drug induced erosions by their 'punched out' appearance. The median number of unhealed biopsy induced mini-ulcers reported on days 4 , 8 , and 15 for all three treatment periods are shown in Fig 2. Neither bFGF nor cimetidine accelerated healing of biopsy induced miniulcers compared with placebo.

\section{Indomethacin induced relapse of biopsy induced mini-ulcers}

Indomethacin therapy was associated with a significant increase in biopsy induced miniulcers from 0 (median, IQR 0-0) preindomethacin to $1(0-4.5)$ post-indomethacin; $\mathrm{p}<0.05$, Fig 3 ). However, there was no significant increase in the number of mini-ulcers after prior treatment with bFGF $(0(0-3 \cdot 25)$ to 0 

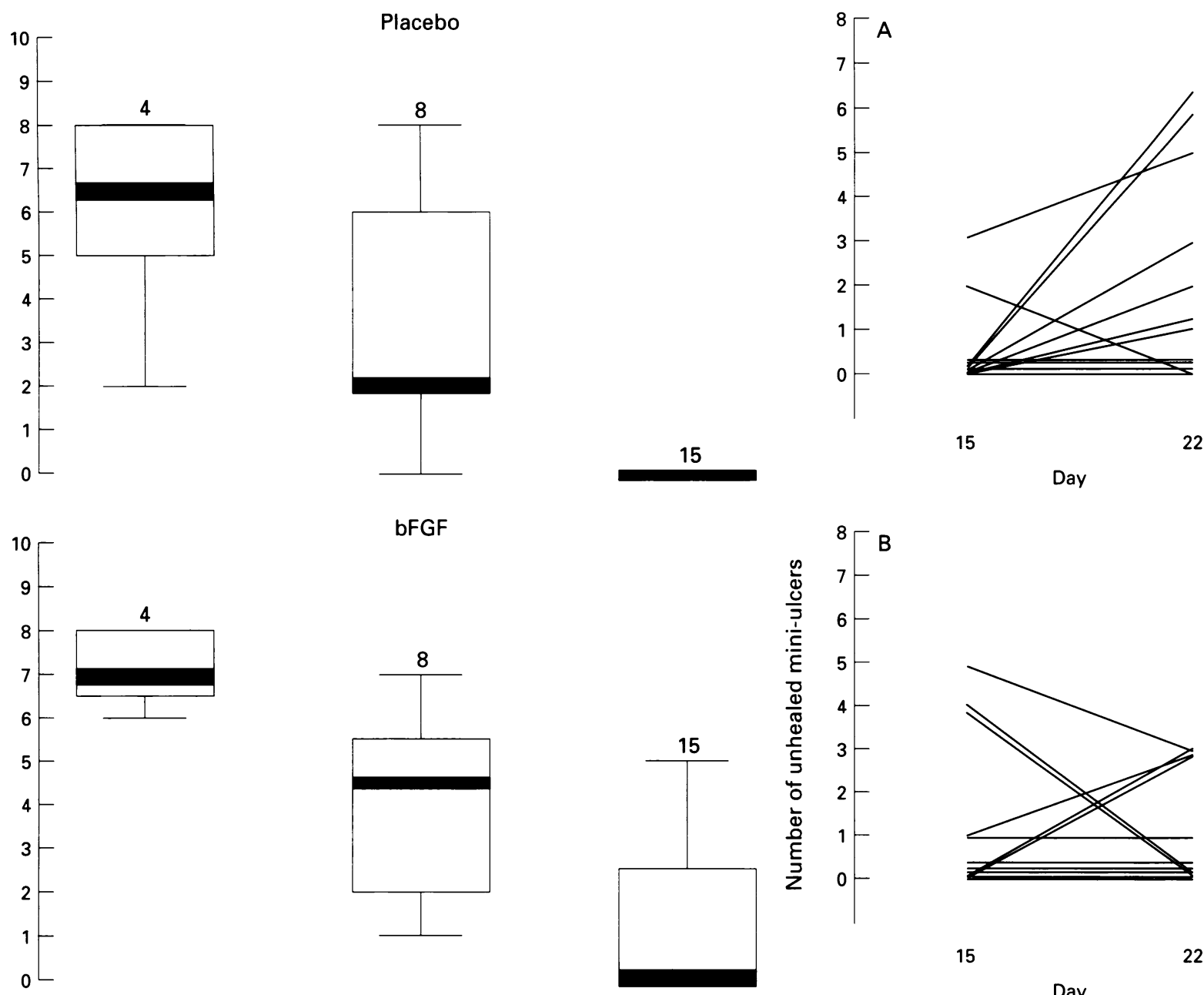

$\mathrm{p}<0.05$
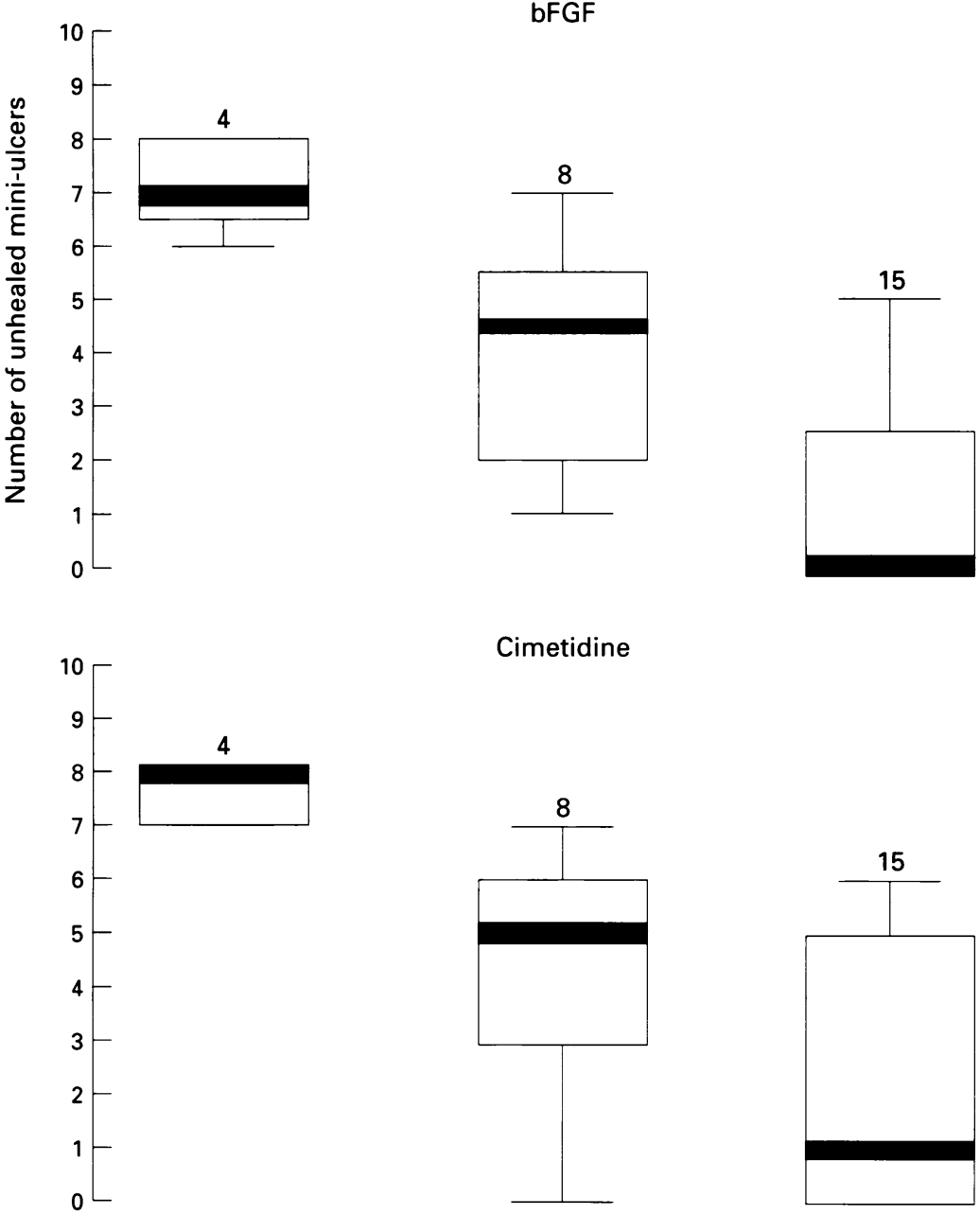

Figure 2: Healing of biopsy induced mini-ulcers. Eight biopsy specimens $(A-H)$ were taken from the antrum on day 1 . The number of unhealed biopsy induced mini-ulcers on days 4 , 8 , and 15 are shown for three treatment periods. Results are expressed as the median value (bold line), interquartile range (box), and data points within 1.5 times the 25 th percentile (bars).

(0-3)) or cimetidine (0 (0-5) to $1(0-3)$; Fig 3). Pairwise comparisons suggested that the miniulcer relapse rate was higher in the placebo group compared with bFGF and cimetidine groups although only at borderline levels of significance ( $p=0.09$ and 0.06 respectively).

Development and healing of aspirin induced gastric and duodenal erosions

The Table shows the median number of erosions in the stomach and duodenum during

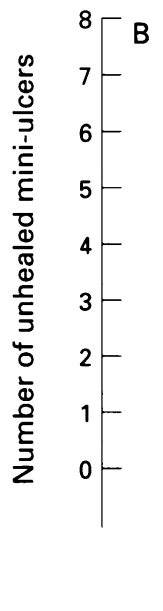

15

22

Day

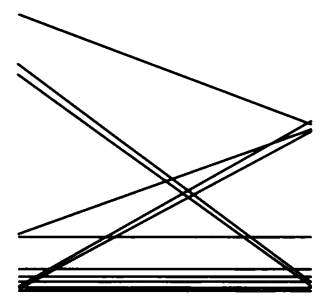

15

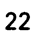

Day
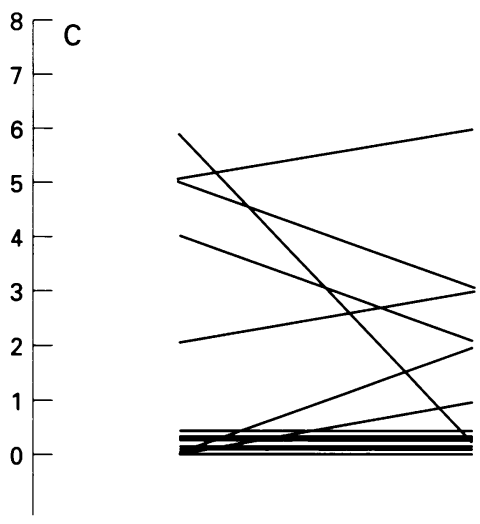

15

22

Day

Figure 3: Relapse of biopsy induced mini-ulcers by indomethacin after treatment with $(A)$ placebo, $(B) b F G F$ or $(C)$ cimetidine. Lines join the number of unhealed miniulcers before and after indomethacin therapy for individual volunteers. Previous treatment with placebo was associated with a significant increase in mini-ulcers $(p<0.05)$ but

there was no relapse of mini-ulcers if indomethacin followed bFGF or cimetidine therapy.

aspirin therapy and the subsequent healing phase (up to day 15). Aspirin caused a significant increase in gastric mucosal injury on day 4 in all three treatment groups $(p<0.05)$. All erosions had healed by day 15 in all three groups. There was no effect of bFGF or cimetidine on prevention or resolution of aspirin induced gastric mucosal injury. Aspirin pro- 
Number of gastric and duodenal erosions present during each treatment period

\begin{tabular}{|c|c|c|c|c|c|}
\hline Drug/Day & 1 & 4 & 8 & 15 & 22 \\
\hline $\begin{array}{l}\text { Stomach } \\
\text { bFGF } \\
\text { cimetidine } \\
\text { placebo }\end{array}$ & $\begin{array}{l}0(0-0) \\
0(0-0) \\
0(0-0)\end{array}$ & $\begin{array}{l}1(0-7)^{\star} \\
3(0 \cdot 5-8)^{\star} \\
2(0-4 \cdot 75)^{\star}\end{array}$ & $\begin{array}{l}0(0-2 \cdot 5) \\
0(0-2 \cdot 5) \\
0(0-0.75)\end{array}$ & $\begin{array}{l}0(0-0) \\
0(0-0) \\
0(0-0)\end{array}$ & $\begin{array}{l}0(0-0) \\
0(0-1 \cdot 5) \\
0(0-1 \cdot 5)\end{array}$ \\
\hline $\begin{array}{l}\text { Duodenum } \\
\text { bFGF } \\
\text { cimetidine } \\
\text { placebo }\end{array}$ & $\begin{array}{l}0(0-0) \\
0(0-0) \\
0(0-0)\end{array}$ & $\begin{array}{l}0(0-2) \\
0(0-1 \cdot 5) \\
0 \cdot 5(0-5) \dagger\end{array}$ & $\begin{array}{l}0(0-0) \\
0(0-0) \\
0(0-0)\end{array}$ & $\begin{array}{l}0(0-0) \\
0(0-0) \\
0(0-0)\end{array}$ & $\begin{array}{l}0(0-2 \cdot 75) \\
0(0-3) \\
1(0-3 \cdot 75) \ddagger\end{array}$ \\
\hline
\end{tabular}

Data are expressed as the median value and interquartile range. ${ }^{\star} \mathrm{p}<0.05$ compared with gastric erosions on day 1 (baseline). $t p<0.05$ compared with duodenal erosions on day 1 (baseline). $\ddagger \mathrm{p}=0.04$ compared with the number of duodenal erosions on day 15 .
Serum thromboxane $B_{2}$ concentrations

Aspirin caused a profound decrease in serum $\mathrm{TXB}_{2}$ in all volunteers within all of the treatment periods (mean (SEM) $\mathrm{TXB}_{2} 424 \cdot 7$ $(51 \cdot 1) \mathrm{ng} / \mathrm{ml}$ before aspirin $v 0.9(0 \cdot 1) \mathrm{ng} / \mathrm{ml}$ after aspirin; $\mathrm{p}<0.0001)$. By day $15, \mathrm{TXB}_{2}$ concentrations had risen to pre-treatment values in every instance (mean (SEM) $\mathrm{TXB}_{2}$ $523.7(29.4) \mathrm{ng} / \mathrm{ml}$, day 15 ; before indomethacin). Indomethacin therapy was also associated with a significant reduction in $\mathrm{TXB}_{2}$ (mean (SEM) $\mathrm{TXB}_{2}$ 90.6 (21.6) ng/ml, after indomethacin; $\mathrm{p}<0.0001$ compared with the value before indomethacin).

duced a significant increase in duodenal erosions but only in the placebo group $(p<0.05)$. There was no discernable acceleration of healing of erosions by bFGF or cimetidine.

\section{Indomethacin induced gastric and duodenal erosions}

As shown in the Table, the number of gastric erosions tended to increase after indomethacin therapy but this was less than with aspirin and did not reach statistical significance in any of the treatment groups. Indomethacin caused an increase in duodenal erosions in all treatment groups although this only reached statistical significance after prior placebo ingestion $(p=0.04)$.

\section{Ex vivo prostaglandin $E_{2}$ synthesis}

Effect of drugs - Aspirin considerably impaired gastric mucosal $\mathrm{PGE}_{2}$ synthesis $(28 \cdot 0$ $(5 \cdot 4) \mathrm{pg} / \mathrm{mg}$ (mean (SEM)) before aspirin $v 3.0$ $(1 \cdot 1) \mathrm{pg} / \mathrm{mg}$ after aspirin; $\mathrm{p}<0 \cdot 005)$. Basic FGF and cimetidine had no effect on aspirin induced depression of $\mathrm{PGE}_{2}$ synthesis. By day $15, \mathrm{PGE}_{2}$ synthesis returned to values similar to those measured before aspirin therapy $(47 \cdot 4$ (13.2) $\mathrm{pg} / \mathrm{mg}$ ). Basic FGF and cimetidine therapy did not affect recovery of $\mathrm{PGE}_{2}$ synthesis. Indomethacin reduced $\mathrm{PGE}_{2}$ production by gastric mucosa significantly (19.7 $(7.0) \mathrm{pg} / \mathrm{mg} ; \mathrm{p}<0.01)$ but not to the same degree as aspirin. Previous bFGF or cimetidine therapy did not abrogate the effect of indomethacin.

Changes at the edge of mini-ulcers - $\mathrm{PGE}_{2}$ synthesis was measured in paired biopsy specimens from biopsy induced mini-ulcers and neighbouring intact mucosa on day 4 (after aspirin) and day 22 (after indomethacin). In all three groups, $\mathrm{PGE}_{2}$ synthesis was increased at the site of a mini-ulcer compared with intact mucosa on day 4 despite aspirin therapy. However this only reached statistical significance when cimetidine was used $(7 \cdot 4(2 \cdot 5) \mathrm{pg} /$ mg (mean (SEM)) mini-ulcer $v 1.9(1.9) \mathrm{pg} /$ $\mathrm{mg}$ intact mucosa; $\mathrm{p}=0.03$ ). Similarly, $\mathrm{PGE}_{2}$ synthesis was increased at mini-ulcers compared with intact mucosa on day 22 . There was a significant increase in $\mathrm{PGE}_{2}$ synthesis only when $\mathrm{bFGF}$ had been given before indomethacin therapy $(26 \cdot 1(10 \cdot 6) \mathrm{pg} / \mathrm{mg}$ mini-ulcer $v 12 \cdot 7(5 \cdot 7) \mathrm{pg} / \mathrm{mg}$ intact mucosa; $\mathrm{p}=0.03)$.

\section{Adverse events}

There were few symptomatic adverse drug events. All were mild and did not neccesitate cessation of drugs. Epigastric discomfort or a hungry sensation was noted during aspirin therapy in three volunteers. Two volunteers complained of headache during indomethacin therapy. Other adverse events included nausea (1), mouth ulcers (1), and one episode of self limiting diarrhoea and vomiting during cimetidine therapy. A pruritic, dry, scaly rash on the flexor aspect of both arms was noted by one volunteer during treatment with TGP-580 in the period between aspirin and indomethacin ingestion. During this time, TGP-580 was detected in serum $(0.41 \mathrm{ng} / \mathrm{ml}$; day 8 and $0.18 \mathrm{ng} / \mathrm{ml}$; day 15). The rash resolved spontaneously after two weeks. There was no past history of skin rash nor did this lesion return during two subsequent treatment periods.

TGP-580 was not detected in any other serum sample taken during the study. Abnormalities in post-study blood investigations were noted in three cases. One female volunteer had a haemoglobin value of $11.4 \mathrm{~g} / \mathrm{dl}$ (MCV $90 \mathrm{fl}$, before study $13.0 \mathrm{~g} / \mathrm{dl}$ ), one male volunteer had mild leucopenia $\left(3.7 \times 10^{9} /\right.$, before study $4.4 \times 10^{9} /$ ) but normal neutrophil and lymphocyte counts and one male volunteer had a slight reduction in neutrophil count $\left(2 \cdot 38\right.$ to $\left.1.62 \times 10^{9} / 1\right)$ without any significant change in total white cell count.

\section{Discussion}

In this study, we developed a model of gastric ulcer relapse, building on an earlier study of mini-ulcer healing ${ }^{20}$ and data from others. ${ }^{21} 22$ We used biopsy sites as mini-ulcers, which are distinguishable endoscopically from NSAID associated erosions and have a different natural history. ${ }^{20}$ In contrast with erosions, biopsy sites have discernable depth. Although the depth of the mucosal defect is limited, it is comparable with many NSAID associated gastric ulcers, which are often very superficial. ${ }^{26}$ Also we have previously shown that misoprostol accelerates healing of mini-ulcers, which is in agreement with clinical data on gastric ulcer healing in patients. ${ }^{5}$

We used aspirin at the time of mini-ulcer formation so that we could pursue a secondary aim of investigating prevention and healing of aspirin induced erosions. However, our pri- 
mary objective was to investigate the influence of the initial healing agent (bFGF or cimetidine) on subsequent mini-ulcer relapse after exposure to another NSAID. In this instance, we used indomethacin (which causes comparatively few gastric erosions ${ }^{27}$ ), which was started two weeks after mini-ulcer formation, at which time, we expected complete healing of mini-ulcers. ${ }^{20}$ During the relapse phase, a total of 19 mini-ulcers relapsed in volunteers who had originally received placebo and who had completely healed gastric mucosa at the start of indomethacin treatment.

Unfortunately, interpretation is complicated by the fact that some subjects had unhealed mini-ulcers at the start of the relapse phase and that there were more unhealed mini-ulcers in the two active treatment groups than the placebo group at this time. However, these differences did not reach statistical significance and the number of unhealed mini-ulcers fell during exposure to indomethacin in the bFGF and cimetidine groups in contrast with the increase in mini-ulcers observed in the placebo group. These findings show that subsequent mini-ulcer relapse in humans varies according to the initial healing regimen. In future studies we intend to avoid the potential confounding issue of healing rate by using a longer healing period to ensure complete healing of miniulcers before the relapse phase.

The finding that previous treatment with bFGF and cimetidine protects against indomethacin induced relapse of mini-ulcers confirms data obtained using a rat model of gastric ulcer relapse (Satoh $\mathrm{H}$, personal communication). We have shown that healing with bFGF is associated with increasing $\mathrm{PGE}_{2}$ synthesis in mini-ulcers after indomethacin therapy. There is evidence that $\mathrm{PGE}_{2}$ is angiogenic in vivo ${ }^{28}$ and controls gastric epithelial cell proliferation. ${ }^{29}$ Basic FGF promotes its own synthesis in cell culture experiments ${ }^{30}$ and there is evidence that bFGF promotes synthesis of the inducible form of cyclooxygenase. ${ }^{31}$ Therefore the effects of bFGF may continue after stopping ingestion. It can be proposed that bFGF improves quality of healing and renders healed mucosa less susceptible to recurrent breakdown by promoting angiogenesis or increasing prostaglandin mediated cytoprotection, or both. The mechanism of action of cimetidine in this instance is less clear. However there are data suggesting that cimetidine may have an immunomodulatory action distinct from other $\mathrm{H}_{2}$ receptor antagonists ${ }^{32} 33$ and 'cytoprotective' properties ${ }^{34}$ and this could explain an alteration of healing mechanisms or increased mucosal resistance to further injury, or both. It should be noted that the cimetidine data are most confounded by the number of unhealed mini-ulcers present at the start of the relapse phase. Our statistical analysis rules out a carry over effect of either bFGF or cimetidine as the explanation for the observed drug effects.

Basic FGF (and cimetidine) did not accelerate healing of biopsy induced miniulcers in this study. A possible explanation is that the time course of healing of biopsy induced mini-ulcers is too short to show any drug effect.
Aspirin induced upper gastrointestinal injury is a well established model in studies with healthy volunteers. Gastric and duodenal injury produced by aspirin in this study was similar to that seen in previous studies using aspirin. Therefore it is unlikely that $\mathrm{NaHCO}_{3}$ treatment in itself (used here to increase intragastric bFGF stability) reduced aspirin induced injury. Moreover, the neutralising activity of $\mathrm{NaHCO}_{3}$ used in this study was 20 $\mathrm{mEq} /$ day which is significantly lower than reported neutralising activity required for peptic ulcer healing $(\sim 120 \mathrm{mEq} / \mathrm{day}) .{ }^{17}$ Aspirin caused profound inhibition of platelet cyclooxygenase- 1 in all cases but serum $\mathrm{TXB}_{2}$ concentrations returned to pre-treatment values before indomethacin therapy and before each new treatment period ruling out any possible carry over effect of aspirin or indomethacin.

The lack of protection against aspirin induced gastric injury by bFGF in this model is in agreement with the lack of effect of subcutaneous bFGF in an acidified aspirin induced injury model in rats. ${ }^{35}{ }^{36}$ In view of the known actions of bFGF (for example, angiogenesis), this is not surprising; exogeneous bFGF would be expected to promote the healing phase of mucosal lesions. ${ }^{16}$ However bFGF (and cimetidine) afforded some protection against aspirin and indomethacin induced duodenal injury, which has not been reported in animal studies. Basic FGF promotes restitution of frog gastric mucosa in vitro $^{37}$ and IEC-6 cell monolayers, ${ }^{38}$ which could explain a cytoprotective action of bFGF in humans.

In this study, adverse drug events were uncommon and not serious. Dyspepsia related to aspirin therapy is well recognised ${ }^{25}$ as is headache with indomethacin. ${ }^{39}$ Unlike previous studies, ${ }^{17} 40$ TGP-580 was detected in serum of one volunteer who developed a rash. Severe gastroduodenal mucosal injury (which could have increased mucosal permeability to TGP-580) was not seen in this instance. There was no evidence of systemic absorption of TGP-580 in any other volunteer.

In summary, we have used biopsy induced mini-ulcers as a model of gastric ulcer in healthy volunteers and showed that previous treatment with both bFGF and cimetidine reduces indomethacin induced relapse of such lesions. There was a small protective effect of bFGF and cimetidine on aspirin and indomethacin induced duodenal (but not gastric) injury. Treatment with bFGF for two weeks was safe but was detected in serum of one volunteer and may have caused a skin rash. Further studies of the effect of bFGF on quality of ulcer healing are required to confirm that bFGF therapy reduces future ulcer relapse. Treatment with bFGF may find a role as an adjunct to treatment with an acid suppressing agent. A combination of these two drugs could promote early ulcer healing and reduce future ulcer relapse rate after treatment is stopped.

1 Hawkey CJ. Non-steroidal anti-inflammatory drugs and peptic ulcers: Facts and figures multiply, but do they add up? $B M \Im$ 1990; 300: 278-84. 
2 Lancaster-Smith MJ, Jaderberg MR, Jackson DA Ranitidine in the treatment of non-steroidal antiinflammatory drug-associated gastric and duodenal ulcers. Gut 1991; 32: 252-6.

3 Hudson N, Taha AS, Russell RI, Sturrock RG, Trye P, Cottrell $\mathrm{J}$, et al. High dose famotidine as healing and maintenance treatment for non-steroidal antiinflammatory drug-associated gastroduodenal ulceration. Gastroenterology 1995; 108: A117.

4 Graham DY, Agrawal NM, Roth SH. Prevention of NSAID-induced gastric ulcer with misoprostol: multicentre, double-blind, placebo-controlled trial. Lancet 1988; ii: $1277-80$.

5 Nicholson PA. A review of the therapeutic efficacy of misoprostol, a prostaglandin $\mathrm{E}_{1}$ analogue. $S \mathrm{Afr}$ Med $\mathcal{F}$ 1988; 74 (suppl): 56-9.

6 Robinson MG, Griffin JW, Bowers J, Kogan FJ, Kogut DG Lanza FL, et al. Effect of ranitidine on gastroduodena mucosal damage induced by non-steroidal antiinflammatory drugs. Dig Dis Sci 1989; 34: 424-8.

7 Hudson N, Balsitis M, Everitt S, Hawkey CJ. Angiogenesis in gastruc ulcers; impaired in patients taking non-steroidal anti-inflammatory drugs. Gut 1995; 37: 191-4.

8 Levi S, Goodlad RA, Lee CY, Stamp G, Walport MJ Wright NA, et al. Inhibitory effect of non-steroidal antiinflammatory drugs on mucosal cell proliferation asso-

9 Bode G, Malfertheiner P, Mader U, Stanescu A Ditschuneit $H$. Fine structure of active and healed duodenal ulcer. Am $\mathcal{F}$ Gastroenterol 1991; 86: 179-86.

10 Littman A, Hanscom DH. The course of recurrent ulcer Gastroenterology 1971; 61: 585-91.

11 Schmassmann A, Tarnawski A, Gerber HA, Flogerzi B, Sanner M, Varga L, et al. Antacid provides better restoration of glandular structures within the gastric ulcer scar than omeprazole. Gut 1994; 35: 896-904.

12 Ernst H, Muller M, Paulus A, Hahn EG, Ell C. Immunohistochemical localization of basic fibroblast growth factor in the normal adult gastrointestinal tract. Eur $\mathscr{f}$ in the normal adult gastrointestinal

13 Hull MA, Cullen DJE, Hawkey CJ. Basic fibroblast growth factor: mucosal levels and therapeutic potential. Gastroenterology 1994; 106: A97.

14 Gospodarowicz D, Neufeld G, Schwiegerer L. Fibroblas growth factor: structural and biological properties. $7 \mathrm{Cell}$ Physiol 1987; 5 (suppl): 15-26.

15 Satoh H, Shino A, Sato F, Inatomi N, Kozai Y, Kato K et al. Role of endogenous and exogenous bFGF in the healing of gastric ulcers in the rat. Gastroenterology 1992; 102: A159.

16 Szabo S, Folkman J, Vattey P, Morales RE, Pinkus GS Kato K. Accelerated healing of duodenal ulcers by oral administration of a mutein of basic fibroblast by oral factor in rats. Gastroenterology 1994;106: 1106-11.

17 Hull MA, Cullen DJE, Hudson N, Hawkey CJ. Basic ibroblast growth factor therapy for non-steroidal antiinflammatory drug-associated gastric ulceration. Gut 1995; 37: 610-2.

18 Lanza FL, Peace KE, Gustitits L, et al. A blinded endoscopic comparative study of misoprostol versus sucralfate and placebo in the prevention of aspirin-induced gastric and duodenal ulceration. $A m \mathcal{F}$ Med 1987; 83 (1A): $37-40$.

19 Daneshmend TK, Prichard PH, Bhaskar NK, Millns P, Hawkey CJ. Use of microbleeding and an ultrathin endoscope to assess gastric mucosal protection by famoendoscope to assess gastric mucosal protec
tidine. Gastroenterology 1989; 97: 944-7.

20 Hull MA, Crouch SL, Wilson AM, Shield MJ, Knifton A, Liu XM, et al. Misoprostol accelerates healing in a human model of gastric ulceration. Gastroenterology 1995; 108: Al18.

21 Scheiman JM, Coffey RJ. Transforming growth factor alpha levels in the human stomach and duodenum: effect of aspirin and acid inhibition. Gastroenterology 1994; 106: A174

22 Stadler P, Armstrong D, Margalith D, Saraga E, Stolte M, Lualdi $\mathrm{P}$, et al. Diclofenac delays healing of gastroduodenal mucosal lesions; double-blind, placebocontrolled endoscopic study in healthy volunteers. Dig Dis Sci 1991; 36: 594-600.

23 Hawkey CJ. Synthesis of prostaglandin $E_{2}$, thromboxane $B_{2}$ and prostaglandin catabolism in gastritis and gastric ulcer Gut 1986; 27: 1484-92.

24 Hawkey CJ, Truelove SC. Effect of prednisolone on prostaglandin synthesis by rectal mucosa in ulcerative colitis: investigation by laminar flow bioassay and radioimmunoassay. Gut 1981; 22: 190-3.

25 Senn S. Cross-over trials in clinical research. Chichester: John Wiley, 1993.

26 Hudson N, Everitt S, Hawkey CJ. Interobserver variation in assessment of gastroduodenal lesions associated with non-steroidal anti-inflammatory drugs. Gut 1994; 35: $1030-2$.

27 Lanza FL, Royer GL, Nelson RS, Chen TT, Seckman CE Rack MF. The effects of ibuprofen, indomethacin, aspirin, naproxen and placebo on the gastric mucosa of aspirin, naproxen and placebo on the gastric mucosa of
normal volunteers; a gastroscopic and photographic normal volunteers; a gastroscopic
study. Dig Dis Sci 1979; 24: 823-8.

28 Form DM, Auerbach R. $\mathrm{PGE}_{2}$ and angiogenesis. Proc Soc Exp Biol Med 1983; 172: 214-8.

29 Baumgartner A, Koelz HR, Halter F. Indomethacin and turnover of gastric mucosal cells in the rat. Am 7 Physio 1986; 250: G830-5

30 Flott-Rahmel B, Gerdes W, Pechan PA, Brysch W, Schlingensiepen K-H, Seifert W. Basic FGF induces its own gene expression in astrocytic and hippocampal cell cultures. NeuroReport 1992; 3: 1077-80.

31 Kawaguchi H, Pilbeam CC, Gronowicz G, Abreu C, Fletcher BS, Herschman HR, et al. Transcriptional induction of prostaglandin $\mathrm{G} / \mathrm{H}$ synthetase- 2 by basic induction of prostaglandin G/H synthetase-2 by basic

32 Peden NR, Robertson AJ, Boyd EJS, Brown RA, Gibbs JH Potts RC, et al. Mitogen stimulation of peripheral blood lymphocytes of duodenal ulcer patients during treatment with cimetidine or ranitidine. Gut 1982; 23: 398-403.

33 Kumar A. Cimetidine: an immunomodulator. Ann Pharmacother 1990; 24: 289-95.

34 Guth PH, Aures D, Paulsen G. Topical aspirin plus $\mathrm{HCl}$ gastric lesions in the rat; cytoprotective effect of prostaglandin, cimetidine and probanthine. Gastroenterology 1979; 76: 88-93.

35 Konturek SJ, Brzozowski T, Majka J, Szlachcic, Bielanski W, Stachura J, et al. Fibroblast growth factor in gastroprotection and ulcer healing: interaction with sucralfate. Gut 1993; 34: 881-7.

36 Brzozowski T, Majka J, Konturek SJ, Bielanski W, Slomiany BL, Garner A. Gastroprotective activity and receptor expression of transforming growth factor alpha, epidermal growth factor and basic fibroblast growth factor in the rat stomach. Eur f Gastroenterol Hepatol 1994; 6: 337-43.

37 Paimela H, Goddard PJ, Carter K, Khakee R, McNeil PL, Ito $S$, et al. Restitution of frog gastric mucosa in vitro: effect of fibroblast growth factor. Gastroenterology 1993; 104: $1337-45$.

38 Dignass AU, Tsunekawa S, Podolsky DK. Fibroblast growth factors modulate intestinal epithelial cell growth
and migration. Gastroenterology 1994; 106: 1254-62.

39 Boardman PL, Hart FD. Side-effects of indomethacin. Ann Rheum Dis 1967; 26: 127-32.

40 Wolfe MM, Bynum TE, Parsons WG, Malone KM, Szabo S, Folkman J. Safety and efficacy of an angiogenic peptide, basic fibroblast growth factor (bFGF) in the treatment of gastroduodenal ulcers: a preliminary report. Gastroenterology 1994; 106: A212. 